\title{
Controlling COVID-19 spread in Jakarta, Indonesia, using quarantine, testing and medical treatment
}

\author{
Ihza Rizkia Fitri*, Toni Bakhtiar \\ Dept. of Mathematics, Division of Operations Research, \\ IPB University, Dramaga, Bogor 16680, Indonesia \\ *Corresponding author: ihza rf99@apps.ipb.ac.id
}

\begin{abstract}
The SARS-CoV-2 outbreak that started in China created COVID-19 pandemic all around the world. This pandemic is declared as a world health crisis by the World Health Organization in 2020. In response to this pandemic, many countries have been conducting various measures to manage the spread of the disease employing lockdown, contacts tracing, and massive testing. As the vaccine and medicine for this virus are under development, the governments all around the world can only apply non-curative measures. With many considerations, especially in the economic sector, governments seem hesitant to apply extensive control measures and this results in a considerable financial loss. In this paper, a generic mathematical model with thirteen compartments is developed, of which it is equipped with five control measures namely quarantine, active carrier identification, recovered individual identification, past infection identification, and medical treatment. We employ the COVID-19 outbreak in Jakarta as a study case to evaluate a series of control scenarios. Optimal control approach is used to find the best control strategy in managing the pandemic. It is suggested that adding the efforts on testing policy and medical treatment 40 days after the first confirmed infection is the most cost-effective strategy with the number of death decreased as much as 60.21 percent of the death cases under initial control strategy.
\end{abstract}

Keywords: COVID-19 cost-effectiveness analysis; medical treatment; modeling; optimal control; quarantine and testing.

\section{Introduction}

The year 2020 has been full of deeply shocks. The most concerning event in this year is the worldwide spread of novel coronavirus. COVID-19 is the kind of infectious disease that is caused by the recent type of coronavirus that has close relations with the other severe acute respiratory syndrome viruses (Gorbalenya et al. 2020). The infection of this virus was first reported in Wuhan, China, at the end of 2019 (Wu et al. 2020). In January, human to human transmission of this virus strain was confirmed ( $\mathrm{Li}$ et al. 2020). This spread of novel coronavirus has been already declared as a global emergency by the World Health Organization in January 2020 (Cucinotta \& Vanelli 2020) and the number of the positive cases keeps increasing.

As this virus spread worldwide through social interaction, countries are debating about how to accelerate the production of vaccine and what intervention that could be used in managing the pandemic. Country's policies in managing the pandemic vary depending on the government's perspective and the socio-cultural context in specific regions and the varying stage of the epidemic. The most common way in managing the pandemic is to apply lockdown policy which includes the heavy travel restriction, the closing of many stores, schools, and offices to prevent the broader spread of coronavirus that is proven to be effective in some cases when it is implemented effectively along with other intervention such as massive testing (Kissler et al. 2020) and the degree of intervention also varies. For example, in Indonesia, the government does not call their policy as lockdown, rather they call the policy as large scale social restriction (Nasruddin \& Haq 2020) with relatively low effectiveness in preventing the mobility of people that may differ with the lockdown policy in Italy and Spain (Tobias 2020). 
This pandemic created massive harms in every aspect of humans' lives. The effects of this pandemic do not only affect humans' lives but also the socio-economic aspect in general. The side effects of this pandemic are mostly the drawback of the control measures to manage the pandemic. For example, the trade problems that include exportation and importation along with the staffing deficiencies are some main concerns as they disrupt the supply chain for businesses (Sohrabi et al. 2020). In an agricultural sector in particular as one primary sector, is also heavily affected by the pandemic as there is a huge drop in consumer spending and even is projected to face continuous challenges for years ahead (Elleby et al. 2020). In the sector of finance, series of social phenomena such as panic selling along with the decrease of consumption, demand, and the utilization of services also create problems like the decline of stock markets globally such as the stock market crash in March 2020 (Mazur et al. 2020). There is also a new problem in the society that includes the psychological problems such as anxiety, fear and worry, and there is a positive correlation between the pandemic and these mental health problems among students in China (Cao et al. 2020). The mental health problem is also a great issue among professionals (da Silva \& Neto 2020). Thus, a comprehensive intervention strategy needs to be undertaken.

Infectious disease management is a multidimensional problem with considerable ways in approaching the problems. In the case of COVID-19, as the problem evolves, we need different approaches conducted simultaneously. A mathematical model has been used widely in the field of epidemiology for multiple purposes such as forecasting, sensitivity analysis, stability analysis, and many more information to manage an infectious. One of the earliest mathematical models was developed by Sir Ronald Ross in 1902 on Malaria, then a simple compartmental mathematical model was developed by Kermack-McKendrick with Susceptible-Infectious-Recovered (SIR) epidemic model in 1927 (Martcheva 2010). This SIR model becomes very influential to the development of mathematical models in the world of epidemiology such as susceptible-exposed-infectious-recovered (SEIR), susceptible-infectioussusceptible (SIS), age-structured model, stochastic model, and many others. Specifically, in the case of COVID-19, there are many pieces of research to model the epidemic starting from a simple susceptibleinfected (SI) model (Demongeot et al. 2020), i.e., the susceptible-infected-recovered-dead (SIRD) model (Anastassopoulou et al. 2020), and susceptible-exposed-infectious-recovered (SEIR) model (He et al. 2020). An age-structured model may expose plenty of information of COVID-19, including the effectiveness of current control strategies (Kimathi et al. 2021). In (Sutton 2010), it was used an age-structured dynamical model to explain the vaccination strategy for pneumococcal infection which can also be applied for the vaccination strategy of COVID-19. As addition, routing problem also plays a big part in pandemic management as it optimizes the energy consumption and duration of distribution process (Ghahremani-Gol et al. 2016). Vehicle routing problem in the context of COVID-19 has been used to optimize the transport of high-risk individual and also the distribution of many urgent necessities such as the personal protective equipment (Pacheco 2020, Zhang et al. 2020).

Various mathematical models have been proposed by scholars to address the transmission of COVID19 during the last two year. While the focus of studies mainly on the model parameters estimation, model behaviour through stability analysis, and model simulation, the use of optimisation-based modeling, i.e., the optimal control framework, has emerged in providing advance analysis towards the disease. Even though that many things can go wrong as pointed out by (Serovaiskii 2004), however, the optimal control theory has positive side in term of methods of solving such problems and practicality in applications (Lenhart \& Workman 2007, Alipour 2017). Optimal control analysis allows evaluating various scenarios of pandemic management. In COVID-19 administration, some recent studies have been conducted in the framework of optimal control theory to assess different measures of control, such as the effect of lockdown, hand washing, side effect controling, and sanitising (Zamir et al. 2021) quarantine and selfisolation (Araz 2021), public health education (Madubueze et al. 2020), health support system (Silva et al. 2021), and possibly with other disease coexistence (Hezam et al. 2021). As the outcome of studies, the best strategies with respect to certain performance criteria are recommended in term of the timing and the degree of interventions.

In this paper we are interested in applying optimal control theory as a framework to comprehend ways to mitigate the spread of COVID-19 in Jakarta, Indonesia. We particularly develop a control model which 
enables us to ensure the effectiveness of quarantine, testing, and medical treatment as control measures, key issues that have not yet been fully examined in the literature. To respect the complex life cycle of the disease, we propose a more comprehensive model by break-downing the primary S, E, I, R compartments into sub-classes pertaining to quarantine policies and unreported cases. In this context, our work broadens the existing works of, for instance, (Aldila et al. 2020), (Zamir et al. 2020), and (Charpentier et al. 2020). To test a series of control strategies against constant-initial one, we perform a cost-effectiveness analysis recommending the best strategy which advises us on how it should be implemented, by suggesting the right times of intervention and the right quantities under most effective cost.

\section{Mathematical model}

For this paper, we develop a new mathematical model and utilize the optimal control approach to find the optimal strategy of interventions. The optimal control approach is widely used in finding an optimal strategy to manage the pandemic. In (Obsu \& Baicha 2020), the model considers four compartments which are susceptible, exposed, infectious, recovered, and virus concentration with three control measures namely the isolation, medical support, and disinfection of the environment. However, this work uses a simple SEIR model with the addition of virus concentration without considering the benefit of testing policy in managing the pandemic. Another common work used consists of the model of susceptible, reported, and unreported (SIRU) model wherein (Araz 2021), the model uses three control measures namely lockdown, quarantine, and isolation. A work that adopted optimal control approach is (Zamir et al. 2020), in which it considers the quarantined, hospitalized, and the possibility of asymptomatic carriers with four control measures, namely stay home, face mask and hand wash, quick case detection, and use of sanitizer. Specifically for the case of COVID-19 in Indonesia, there are several works available, such as the work of (Aldila et al. 2020), which uses SEIR model with the addition of undetected asymptomatic and detected asymptomatic carriers with the study case in Jakarta, the work of (Annas et al. 2020) which exploits the basic SEIR model, and also the work of (Aldila et al. 2020) which employs the optimal control approach with four control measures which are the use of medical mask, hospitalization, rapid test, and medical treatment.

\subsection{Assumptions}

In this current work, we developed a new model considering the quarantine policy, testing policy and medical treatment. There are several key features provided by the model. The first thing is that the quarantine policy is represented using compartments attached to the original SEIR model and we also consider the quarantined recovered individuals who are not aware that they have recovered from the virus infection. This representation is important as the quarantined individuals have very limited mobility and limited ability to create economic values as not everyone is able to conduct work from home, especially the population in the middle to lower economic class (Martin et al. 2020, Bonaccorsi et al. 2020). The second unique feature is the testing policies that are applied not only to identify the active carriers, but also the recovered individuals. The third feature is that medical treatment in the current model serves as the treatment for the existing symptoms caused by the virus. In this set-up, medical treatment only reduces the mortality caused by the virus. This is considering the fact that COVID-19 medicine is not yet available (Jean et al. 2020). Plenty of factors may affect the dynamics of process in real-life condition, and to accommodate these interests and to simplify the phenomenon, we introduced several main assumptions as follow:

1. The population can always be categorized into thirteen compartments defined in the model. The model consists of mainly five classes which are the susceptible, exposed, infected, recovered, and removed population. Quarantine is the method to prevent social interaction and avoid pathogen transmission.

(a) The first class is the susceptible population which consists of roaming susceptible population $S(t)$ and quarantined susceptible population $S_{Q}(t)$. The susceptible population is the individuals who are vulnerable to disease infection. To prevent the infection, susceptible population may opt into quarantine. In this case, the coronavirus is transmitted through infected secretions or commonly known as droplet (WHO 2020), while some droplets can be small enough and become 
aerosol (Jayaweera et al. 2020, Setti et al. 2020, Wilson et al. 2020). Thus, the susceptible population can be exposed and in the end infected by the virus when contact or interaction with exposed or infected population happens.

(b) The second class is the exposed population which are roaming exposed population $E_{U}(t)$ and the quarantined exposed population $E_{Q}(t)$. The exposed population is the individuals who are exposed to the disease and the pathogen has already transmitted to these individuals. The roaming population may transmit the disease to the susceptible population. However, the saturation of the pathogen is still not enough to be detected by the diagnostic test (Mina et al. 2020). Exposed individuals become an infected individual with a rate of $\beta$. This phase can also be interpreted as the incubation period.

(c) The third class is the infected population which consists of the roaming unreported infected population $I_{U}(t)$, the quarantined unreported infected population $I_{Q}(t)$, and the confirmed infected population $I_{C}(t)$ who are already tested. This population is defined as the individuals who suffer the disease and the saturation of the pathogen is already enough to be detected by the diagnostic test. This population is also the population that could recover from the disease. The mortality rate of the infected individuals is $\mu$, while the recovery rate is $\gamma$.

(d) The fourth class is the recovered population which consists of an unidentified recovered population $R_{U}(t)$ that comes from the roaming unreported infected population, the quarantined recovered population $R_{Q}(t)$ that comes from the quarantined infected population, the recovered confirmed infected population $R_{I}(t)$ which comes from the confirmed or identified active carriers, but have not been tested yet, and the confirmed recovered population $R_{C}(t)$ that is already tested either from the recovered confirmed infected population or the roaming and quarantined recovered population (Hoffman et al. 2020). The recovered population is the individuals who have recovered from the disease and developed immunity to the disease. In this paper, we assumed that the recovered population cannot transmit or become a host of the virus.

(e) The fifth class is the discarded population or death case. We here assumed that the mortality is only applied to the infected population. This population consists of the untested death $D_{U}(t)$ and the tested death $D_{C}(t)$. We do not take into account the natural death incidents as we consider a relatively short period of time, i.e., ten months. Thus, the rate $\mu$ that outflows from an infected class denotes the COVID-19 induced mortality rate.

2. It is assumed that the system is a closed system. This is to say that immigration is not considered. This is particularly the case when travel restriction is put. Natural birth is also not considered in this model as we analyzed the situation on a short time frame.

3. It is assumed that the spread of the disease happens through the interaction among the population with the transmission rate of $\alpha$. By defining the roaming infectious population $I_{F}(t)$ and the total roaming population $F(t)$ as follow:

$$
\begin{aligned}
I_{F} & =E_{U}+I_{U}, \\
F & =S+R_{U}+R_{C}+I_{F},
\end{aligned}
$$

the transfer rate from the susceptible compartment becomes $\alpha I_{F} / F$.

4. Roaming population goes to quarantine with the transfer rate of $\varepsilon_{j} u_{1}(t)$, where $u_{1}(t)$ represents the quarantine policy effort that in real-life may include campaign and enforcement, while $\varepsilon_{j}$ is the effectiveness of the policy for $j \in\{S, E, I, R\}$. Quarantined individuals go back to roaming condition with the transfer rate of $\eta_{j}$ for $j \in\{S, E, I, R\}$.

5. The testing policy is represented by $u_{i}(t)$ for $i=2,3,4$. These variables reflect the testing policy to identify the active carriers of COVID-19, recovered individuals, and past infections respectively for $\tau$ as the testing policy effectiveness. 
Table 1. State and control variables description.

\begin{tabular}{lll}
\hline Variable & Description & Unit \\
\hline$S$ & the number of roaming susceptible population & people \\
$S_{Q}$ & the number of quarantined susceptible population & people \\
$E_{Q}$ & the number of quarantined exposed population & people \\
$I_{U}$ & the number of roaming unreported infected population & people \\
$I_{Q}$ & the number of quarantined unreported infected population & people \\
$I_{C}$ & the number of reported infected population & people \\
$R_{U}$ & the number of roaming unreported recovered population & people \\
$R_{Q}$ & the number of quarantined unreported recovered population & people \\
$R_{I}$ & the number of recovered confirmed infected population & people \\
$R_{C}$ & the number of reported recovered population & people \\
$D_{U}$ & the number of unreported death & people \\
$D_{C}$ & the number of reported death & people \\
\hline$u_{1}$ & the proportion of quarantined individual & - \\
$u_{2}$ & the proportion of active carrier identification (testing) & - \\
$u_{3}$ & the proportion of recovered individual identification (testing) & - \\
$u_{4}$ & the proportion of past infection identification (testing) & - \\
$u_{5}$ & the proportion of non-curative medical treatment & - \\
\hline
\end{tabular}

6. The control $u_{5}(t)$ denotes the medical support given for the confirmed active carriers with the effectiveness of $\varepsilon_{\mu}$ in lowering the mortality rate because of the disease. The medical treatment is exclusively given to the confirmed active carriers $I_{C}(t)$.

7. The unreported death $D_{U}(t)$ and the unreported recovery $R_{U}(t)$ will not be tested.

8. It is assumed that testing can be conducted simultaneously and results can be obtained on the same day as the test. Multiple testing can also be conducted on the same day and we assume it does not affect the effectiveness of the tests.

9. It is assumed that there is no limitation in conducting the control strategies. This means that the only consideration is the amount of capital that needs to be spent in a vacuum.

\subsection{SEIR-QD model}

Under the aforementioned assumptions, we then constructed the compartmental model presented in Figure 1 with the description of all state variables are given in Table 1 . The arced lines represent the transfer of individuals from one compartment to another, and next to the lines, there are the transfer rates between compartments. Based on this schematic diagram, we then formulated the analytical form of the SEIR-QD model in term of a system of nonlinear ordinary differential equations.

$$
\begin{aligned}
\frac{d S}{d t} & =\eta_{S} S_{Q}-\left(\frac{\alpha I_{F}}{F}+\varepsilon_{S} u_{1}\right) S+\delta\left(R_{U}+R_{C}\right), \\
\frac{d S_{Q}}{d t} & =\varepsilon_{S} u_{1} S+\delta R_{Q}-\eta_{S} S_{Q}, \\
\frac{d E_{U}}{d t} & =\frac{\alpha I_{F}}{F} S+\eta_{E} E_{Q}-\left(\beta+\eta_{E} u_{1}\right) E_{U}, \\
\frac{d E_{Q}}{d t} & =\varepsilon_{E} u_{1} E_{U}-\left(\beta+\eta_{E}\right) E_{Q}, \\
\frac{d I_{U}}{d t} & =-\left(\gamma+\mu+\varepsilon_{I} u_{1}+\tau u_{2}\right) I_{U}+\eta_{I} I_{Q}+\beta E_{U}, \\
\frac{d I_{Q}}{d t} & =-\left(\gamma+\eta_{I}+\mu+\tau u_{2}\right) I_{Q}+\varepsilon_{I} u_{1} I_{U}+\beta E_{Q},
\end{aligned}
$$




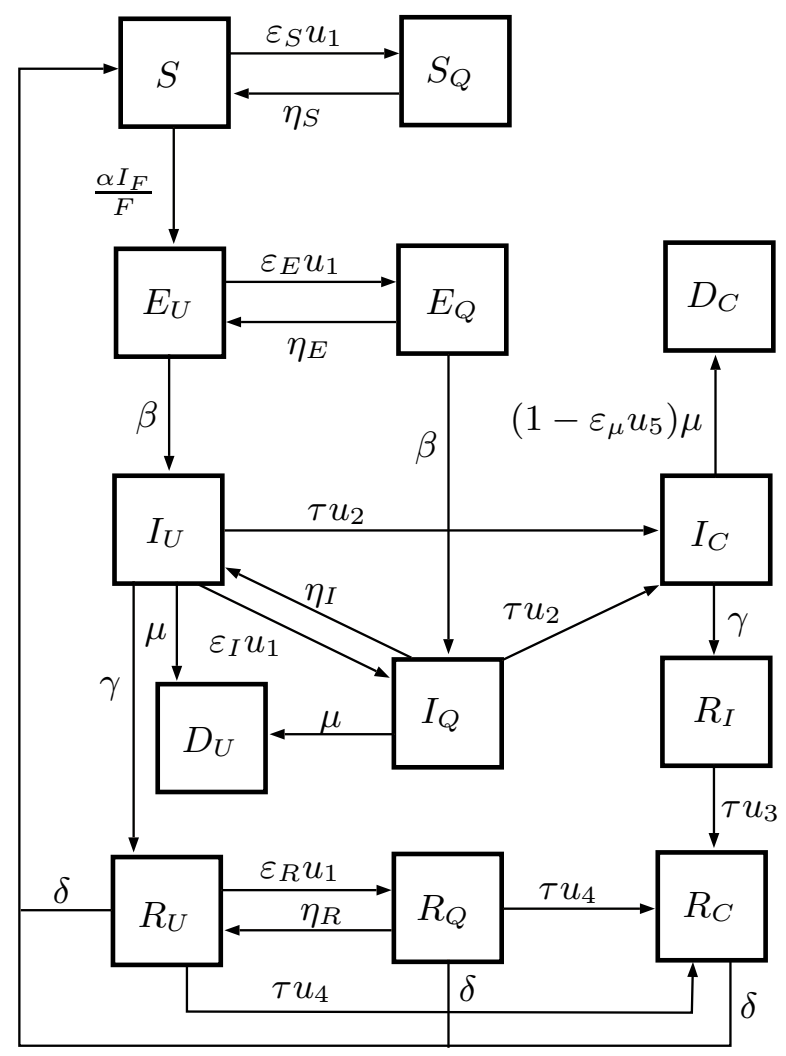

Fig. 1. SEIR-QD compartmental model.

$$
\begin{aligned}
\frac{d I_{C}}{d t} & =-\left(\gamma+\left(1-\varepsilon_{\mu} u_{5}\right) \mu\right) I_{C}+\tau u_{2}\left(I_{U}+I_{Q}\right), \\
\frac{d R_{U}}{d t} & =-\left(\delta+\varepsilon_{R} u_{1}+\tau u_{4}\right) R_{U}+\eta_{R} R_{Q}+\gamma I_{U}, \\
\frac{d R_{Q}}{d t} & =-\left(\delta+\eta_{R}+\tau u_{4}\right) R_{Q}+\varepsilon_{R} u_{1} R_{U}+\gamma I_{Q}, \\
\frac{d R_{I}}{d t} & =\gamma I_{C}-\tau u_{3} R_{I}, \\
\frac{d R_{C}}{d t} & =\tau u_{4}\left(R_{Q}+R_{U}\right)+\tau u_{3} R_{I}-\delta R_{C}, \\
\frac{d D_{U}}{d t} & =\mu\left(I_{U}+I_{Q}\right), \\
\frac{d D_{C}}{d t} & =\mu\left(1-\varepsilon_{\eta} u_{5}\right) I_{C} .
\end{aligned}
$$

In model (3)-(15), we denote by $u_{i}$ for $(i=1,2,3,4,5)$, the control variables, where control by quarantine/lockdown campaign is denoted by $u_{1}$, active carrier identification by $u_{2}$, recovered individual identification by $u_{3}$, past infection identification by $u_{4}$, and non-curative medical treatment by $u_{5}$. All control variables are bounded:

$$
0 \leq u_{i}(t) \leq 1,
$$

for $i=1,2,3,4,5$ and for all $t \in[0, T]$, where $T$ is the end of control period. Due to some reasons, such as the efficiency or likelihood levels of the control measures to be implemented, any control can not practically be implemented in full intensity, i.e., $u_{i}(t)=1$. To conform this issue we introduce a number of parameters representing the limitedness of control application. We denote by $\varepsilon_{S}, \varepsilon_{E}, \varepsilon_{I}, \varepsilon_{R}$ the likelihood of the $S, E, I, R$ individuals to be quarantined, respectively, by $\varepsilon_{\mu}$ the effectiveness of medical treatment, and by $\tau$ the effectiveness of the testing policy. 


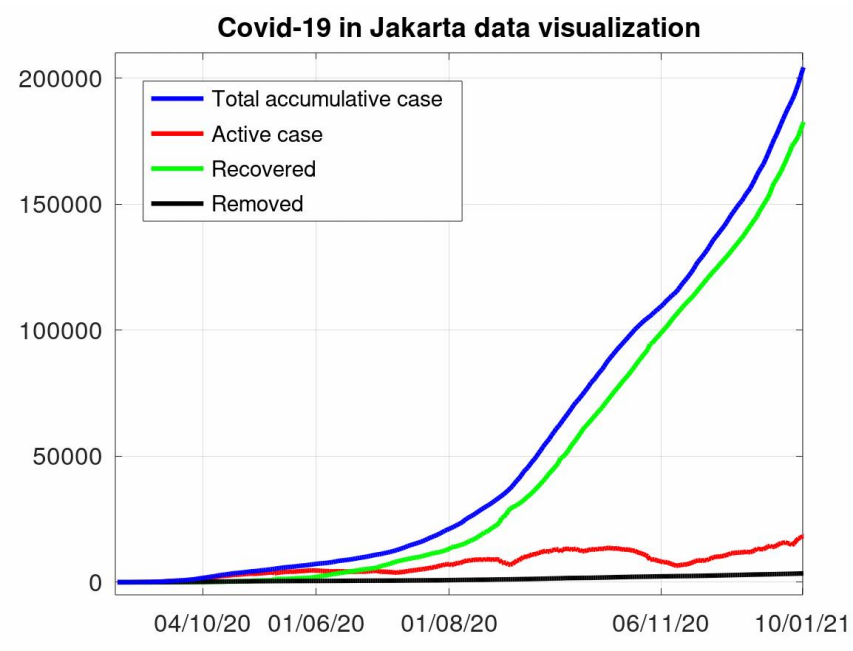

Fig. 2. Visualization of COVID-19 data in Jakarta from March 1st, 2020 to January 10th, 2021.

\section{Model-data fit}

For the purpose of model-data fit, we used the data from Jakarta Open Data (Dinas Kesehatan DKI Jakarta 2020, Pemda DKI Jakarta 2020) which provides the daily report on the death, positive case, and recovery from March 1st, 2020 which was a few days before the first confirmed case of COVID-19 in Jakarta until January 10th, 2021. The time-series of this data is given in Figure 2. Parameters estimation was conducted by fitting the available data into a simplified SEIR model. By using the method of least squares and the best fit curve that minimizes the error between the fitted data and the actual data, we estimated the unknown parameters, such as the infection rate $\alpha$, the recovery rate $\gamma$, and the mortality rate $\mu$. In this step we follow, for instance, (Mehra et al. 2020) and (Bentout et al. 2020).

Another thing important to note is that there is a suspicion that COVID-19 invaded Jakarta even earlier than the first identified infection. This suspicion is also the reason for some precautions conducted by the government of Indonesia in January 2020 (Putri 2020). In this current study, we assume that the first exposure of virus happened in the middle of February 2020. Thus, by the time of the first confirmed infection which we assumed to be $t=0$, it is intuitive to say that

$$
S(0)=S^{0}<S_{\text {init }}, E_{U}(0)=E_{U}^{0} \geq 0, I_{U}(0)=I_{U}^{0} \geq 0, R_{U}(0)=R_{U}^{0} \geq 0, D_{U}(0)=D_{U}^{0}>0,
$$

as there is no control effort applied from the first undetected COVID-19 infection up until the first confirmed case of COVID-19 infection. In (17) $S_{\text {init }}$ is the total population of Jakarta (Jayani 2019). It is also intuitive to set

$$
E_{Q}(0)=E_{Q}^{0}=0, I_{Q}(0)=I_{Q}^{0}=0, I_{C}(0)=I_{C}^{0}=0, R_{I}^{0}=R_{Q}^{0}=0, D_{C}(0)=D_{C}^{0}=0 .
$$

as there were no social limitation policy or testing before the first confirmed positive case.

In fact, there are three primary control efforts introduced in this paper, namely quarantine policy $\left(u_{1}\right)$, testing policy $\left(u_{2}, u_{3}, u_{4}\right)$, and medical treatment $\left(u_{5}\right)$. Quarantine is a policy that limits the mobility of people within a certain region. In the context of infectious disease spread through the interaction among people, quarantine or lockdown policy is highly important to prevent virus transmission. It is commonly known that lockdown can suppress the spread of the virus with some side effects in many areas such as the psychological condition of the people as well as economic condition (Atalan 2020). For testing, there are diagnostic testing to identify the infected individuals and the test to identify the recovered individuals. In the case of COVID-19 specifically, the most accurate test available is the reverse transcription-polymerase chain reaction (RT-PCR) which is used to detect the existence of the virus within the body (Mardani et al. 2020). There is also a diagnostic test to identify the recovered individuals. To identify past infection, the antibody test is commonly used (Deeks et al. 2020). The 
Table 2. Parameters description and values.

\begin{tabular}{|c|c|c|c|}
\hline Parameter & Description & Unit & Value \\
\hline$\alpha$ & The infection rate of the pathogen & $1 /$ day & 0.319 \\
\hline$\beta$ & $\begin{array}{l}\text { The development rate of the pathogen once it is transmitted to a } \\
\text { new host }\end{array}$ & 1/day & 0.25 \\
\hline$\gamma$ & The recovery rate of infected individuals & $1 /$ day & 0.11 \\
\hline$\mu$ & The mortality rate of infected individuals & $1 /$ day & 0.018 \\
\hline$\delta$ & Fading immunity rate & 1/day & 0 \\
\hline$\eta_{S}$ & The return of susceptible individuals from quarantine & $1 /$ day & $1 / 14$ \\
\hline$\eta_{E}$ & The return of exposed individuals from quarantine & $1 /$ day & $1 / 14$ \\
\hline$\eta_{I}$ & The return of infected individuals from quarantine & 1/day & $1 / 14$ \\
\hline$\eta_{R}$ & The return of recovered individuals from quarantine & 1/day & $1 / 14$ \\
\hline$\varepsilon_{S}$ & The likelihood of the susceptible individual to enter quarantine & 1/day & 0.7 \\
\hline$\varepsilon_{E}$ & The likelihood of the exposed individual to enter quarantine & 1/day & 0.7 \\
\hline$\varepsilon_{I}$ & The likelihood of the infected individual to enter quarantine & $1 /$ day & 0.7 \\
\hline$\varepsilon_{R}$ & The likelihood of the recovered individual to enter quarantine & 1/day & 0.7 \\
\hline$\varepsilon_{\mu}$ & The effectiveness of medical treatment & - & 0.95 \\
\hline$\tau$ & The effectiveness of the testing policy & 1/day & 0.1353 \\
\hline
\end{tabular}

antibody test also needs to be followed by RT-PCR to make sure that one is already recovered. However, the initial definition of a recovered individual must be the individual who has been confirmed to be infected by the virus, and the last diagnostic test shows a negative result. Thus, the control $u_{4}$ is zero initially as an antibody test is not considered as a means to identify past infection. To reduce the mortality rate of infected individuals, especially those who have developed symptoms, medical treatment is also needed. In the case of COVID-19, the most common treatment is the support using ventilators as the saturation of oxygen decreases. It is important to be noted that especially during the time frame used in this paper, the treatment for COVID-19 so far only serves to treat the symptoms of the disease, not to cure the disease. With that being said, medical treatment does not significantly affect the recovery rate of infected individuals.

Table 3. Constant controls descriptions and values.

\begin{tabular}{cccccc}
\hline \multirow{2}{*}{ Control } & \multicolumn{5}{c}{ Time Frame } \\
\cline { 2 - 6 } & 1 & 2 & 3 & 4 & 5 \\
\hline$u_{1}$ & 0.4980 & 0.7425 & 0.6425 & 0.5025 & 0.2535 \\
$u_{2}$ & 0.0692 & 0.0502 & 0.0326 & 0.0434 & 0.0641 \\
$u_{3}$ & 0.0434 & 0.0319 & 0.0474 & 0.1044 & 0.1199 \\
$u_{4}$ & 0 & 0 & 0 & 0 & 0 \\
$u_{5}$ & 0.5150 & 0.9500 & 0.9980 & 0.9810 & 0.9700 \\
\hline
\end{tabular}

It is also important to note that from the first confirmed case in March 2020 up until January 2021, and thus in this paper, we divided the timeline into five time frames. This kind of division is also applied in (Aldila et al. 2020). We then employed this approach to estimate the model parameters. The value of parameters that used for the constant control simulation is presented in Table 3, while the other parameter values are presented in Table 2. We mainly collected the parameter values from (Anastassopoulou $e t$ al. 2020). We also take the median time of four days from exposure to symptom occurrence (Guan et al. 2020).

For the purpose of the model fit, we divided the timeline into three parts. This is considering the policy dynamics of the regional government. The first time frame is from day 0 to day 40 , the second time frame is from day 40 to day 92 , the third time frame is from 92 to 153 , the fourth time frame is from 153 to 250, and the last time frame is from 250 to 315 . Between each time frame, the policies' 


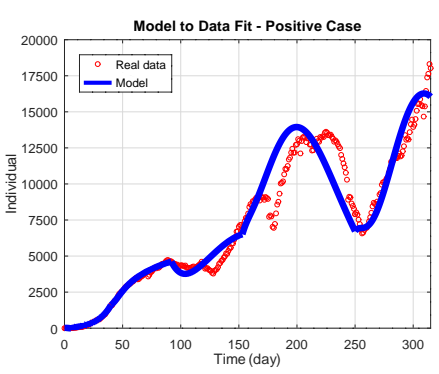

(a) infected individuals

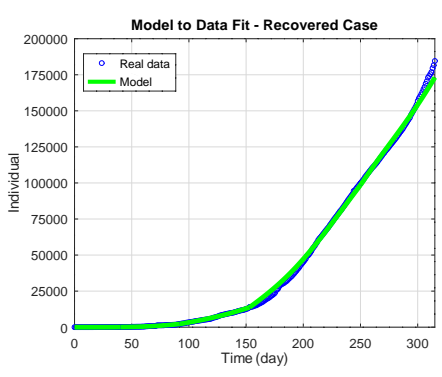

(b) recovered individuals

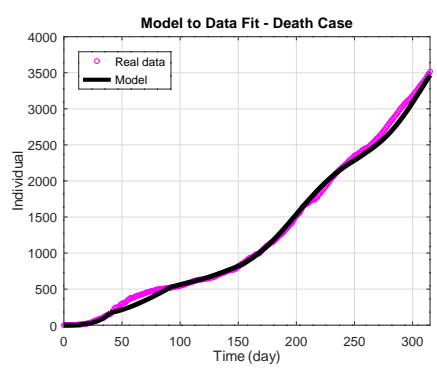

(c) removed (dead) individuals

Fig. 3. Model fit to the real data.

dynamics are changed and adjusted. Figures $3 a, 3 b$, and $3 c$ show that with the choice of parameters values, model SEIR-QD can follow the data quite well. However, it is important to note that this model fitting served two main purposes which are finding the initial adjusted parameters and estimating a basis for a cost comparison. Thus, the comparison between the optimal control and the initial control can easily be understood.

An important thing to note regarding the policies is that the complexity and the exact definitions are not perfectly represented. In this paper, for the model to data fit, we do not consider the antibody test to identify the recovered individuals as the definition of recovered individual in Indonesia is those who have been tested positive and tested negative, not those with immunity. In this paper also, the identification of active carriers is not conducted using multiple steps such as what happened in Indonesia where antibody test was commonly used to get travel permission and in other words, it was used to certify someone as non-carrier of coronavirus (Sebayang 2020, Nurita 2020).

\section{Control problem and optimality conditions}

Optimal control framework can be exploited to characterize the best control values at every point of time $t$ with respect to an objective functional as a performance index of the system with controls.

\subsection{Control problem}

In this study we consider the following objective functional:

$$
J=\int_{0}^{T}\left(B_{1}\left(S+S_{Q}\right)-B_{2}\left(D_{U}+D_{C}\right)-\left(C_{1} u_{1}^{2}+C_{2} u_{2}^{2}+C_{3} u_{3}^{2}+C_{4} u_{4}^{2}+C_{5} u_{5}^{2}\right)\right) d t
$$

where for $B_{1}, B_{2}$ and $C_{i}(i=1,2, \ldots, 5)$ are the balancing cost weights of the performance index that represents the relative importance and/or cost for the corresponding variables. The performance index (19) consists of three parts. The first part relates to the number of susceptible individuals. This part is considered in the performance index as there is nothing we can do to cure the disease once someone is infected by the virus, thus, no control is made directly to minimize the infected population, and thus it is logical to put the susceptible population in the performance index. The second part consists of the sub-populations we want to minimize, namely the discarded individuals (death cases). The last part is the cost associated with the control efforts. Thus the objective of the control application is to find $u_{i} \in \mathbb{U}$ that maximizes $J$, where $\mathbb{U}$ is the set of all admissible controls given by

$$
\mathbb{U}=\left\{u \mid u_{i}(t) \text { is Lebesque measurable for } u_{i}(t) \in[0,1], t \in[0, T]\right\},
$$

where $u=\left(u_{1}, \ldots, u_{5}\right)^{T}$. The control objectives can be attained by maximizing the number of susceptible individuals and in the same time minimizing the number of the death cases as well as the costs associate to the control effort. Since all control variables are related to the transfer rate, then bounded control policies must be implemented as given in (16). 


\subsection{Optimality conditions}

To facilitate the analysis, we denote by $f$ the integrand function of functional (19) and by $g_{i}$ the right-hand side of model (3)-(15) for $i=1,2, \ldots, 13$. The Hamiltonian is then provided by

$$
H=f+\sum_{i=1}^{13} p_{i} g_{i},
$$

where $p_{i}=p_{i}(t)$ for $i=1,2, \ldots, 13$ are the adjoin functions corresponding to each equation in the model. These adjoin functions are just like the Lagrange multipliers in the static optimization. The control problem is then represented as the optimization problem of the Hamiltonian function. From (21), we provided the optimality conditions following the Pontryagin maximum principle (Pontryagin $e t$ al. 1986):

$$
\begin{aligned}
& \frac{\partial H}{\partial u_{i}}=0, \\
& \frac{d x_{j}}{d t}=\frac{\partial H}{\partial p_{j}}, \\
& \frac{d p_{j}}{d t}=-\frac{\partial H}{\partial x_{j}},
\end{aligned}
$$

for $i=1,2, \ldots, 5$, for $j=1,2, \ldots, 13$, and for $x_{j} \in\left\{S, S_{Q}, \ldots, D_{C}\right\}$. Condition (22) suggests that the optimal controls for the system can be obtained by deriving the Hamiltonian function with respect to each control variable. Condition (23) ensures that the system state (3)-(15) is obeyed. Condition (24) produces the so-called adjoin system which must be simultaneously satisfied by the control, adjoin, and state variable. Since we tacitly assumed that the state variables are all free at terminal time, then the adjoin variables must adhere the following transversality conditions (Seierstad \& Sydsæter 1987):

$$
p_{j}(T)=0,
$$

for $j=1,2, \ldots, 13$.

Since we apply bounded controls and non-negative initial conditions, then non-negative bounded solutions to the system (3)-(15) exist. In addition, since the integrand function of functional (19) is concave with respect to $u \in \mathbb{U}$ with closed admissible control set $\mathbb{U}$ given in (20), the system (3)-(15) is linear in the control variables $u_{i}$, and the state variables are all bounded, then the existence of optimal control $u_{i}^{*}$ is guaranteed (Fleming \& Rishel 1975). We then derive the solution for the optimal controls using (22) as follow:

$$
\begin{aligned}
& u_{1}=-\frac{1}{2 C_{1}}\left(\left(p_{1}-p_{2}\right) \varepsilon_{S} S+\left(p_{3}-p_{4}\right) \varepsilon_{E} E_{U}+\left(p_{5}-p_{6}\right) \varepsilon_{I} I_{U}+\left(p_{8}-p_{9}\right) \varepsilon_{R} R_{U},\right. \\
& u_{2}=-\frac{\tau}{2 C_{2}}\left(\left(p_{5}-p_{7}\right) I_{U}+\left(p_{6}-p_{7}\right) I_{Q}\right), \\
& u_{3}=-\frac{\tau}{2 C_{3}}\left(p_{10}-p_{11}\right) R_{I} \\
& u_{4}=-\frac{\tau}{2 C_{4}}\left(p_{8} R_{U}+p_{9} R_{Q}-p_{11}\right), \\
& u_{5}=-\frac{\varepsilon_{\mu} \mu}{2 C_{5}}\left(p_{13}-p_{7}\right) I_{C} .
\end{aligned}
$$

The equations (26)-(30) represent the optimal control function for three distinct control efforts. From these we now have a brief description of how the controls should be applied. The effort to campaign on quarantine depends positively on the roaming population, the effort to testing depends on the guessed unreported infected individuals, and the medical treatment depends on the number of people that are already reported. The adjustment on the controls is done by the corresponding adjoin functions. We can also see that the more effective a control, the more the control should be conducted. The associated costs to the control efforts on the other hand impact differently as the more expensive the costs are, the lesser the controls should be conducted. However, we also need to consider the bounds of the control functions in (16). Thus, the set of optimal control variables should be rewritten as presented as follow:

$$
u_{i}^{*}=\min \left\{1, \max \left\{0, u_{i}\right\}\right\},
$$


for $i=1,2, \ldots, 5$, and $u_{i}$ are given in (26)-(30), respectively. By expressing as (31), we may calculate the optimal control variables as numerical bounded solution.

While condition (23) gives back the dynamical model (3)-(15) that we refer as a state system, (24) produces the adjoin system corresponding to the state system. The adjoin system is formulated as the system of non-linear differential as follow:

$$
\begin{aligned}
\frac{d p_{1}}{d t} & =-B_{1}+\left(p_{1}-p_{3}\right)(F-S) \frac{\alpha I_{F}}{F^{2}}+\left(p_{1}-p_{2}\right) \varepsilon_{S} u_{1} \\
\frac{d p_{2}}{d t} & =-B_{1}+\left(p_{2}-p_{1}\right) \eta_{S} \\
\frac{d p_{3}}{d t} & =\left(p_{1}-p_{3}\right)\left(F-E_{U}\right) \frac{\alpha I_{F}}{F^{2}}+\left(p_{3}-p_{4}\right) \varepsilon_{E} u_{1}+\beta\left(p_{3}-p_{5}\right) \\
\frac{d p_{4}}{d t} & =\left(p_{4}-p_{3}\right) \eta_{E} \\
\frac{d p_{5}}{d t} & =\left(p_{1}-p_{3}\right)\left(F-I_{U}\right) \frac{\alpha I_{F}}{F^{2}}+\left(p_{5}-p_{6}\right) \varepsilon_{I} u_{1}+\left(p_{5}-p_{7}\right) \tau u_{2}+\gamma\left(p_{5}-p_{8}\right)+\mu\left(p_{5}-p_{12}\right), \\
\frac{d p_{6}}{d t} & =\left(p_{6}-p_{5}\right) \eta_{I}+\left(p_{6}-p_{7}\right) \tau u_{2}+\gamma\left(p_{6}-p_{9}\right)+\mu\left(p_{6}-p_{1} 2\right), \\
\frac{d p_{7}}{d t} & =\mu\left(p_{7}-p_{13}\right)\left(1-\varepsilon_{\mu} u_{5}\right)+\gamma\left(p_{7}-p_{9}\right) \\
\frac{d p_{8}}{d t} & =\delta\left(p_{8}-p_{1}\right)+\left(p_{3}-p_{1}\right) \frac{\alpha I_{F} S}{F^{2}}+\left(p_{8}-p_{9}\right) \varepsilon_{R} u_{1}+\left(p_{8}-p_{11}\right) \tau u_{4}, \\
\frac{d p_{9}}{d t} & =\delta\left(p_{9}-p_{2}\right)+\eta_{R}\left(p_{9}-p_{8}\right)+\left(p_{9}-p_{11}\right) \tau u_{4}, \\
\frac{d p_{10}}{d t} & =\left(p_{11}-p_{10}\right) \tau u_{3}, \\
\frac{d p_{11}}{d t} & =\delta\left(p_{11}-p_{1}\right) \\
\frac{d p_{12}}{d t} & =B_{2} \\
\frac{d p_{13}}{d t} & =B_{2} .
\end{aligned}
$$

By end of this section, we have discussed the existence of a set of optimal controls and the derivation of the optimal controls, the state system, and the adjoin system as well as their transversality conditions. It is shown that the first control which is quarantine policy depends on the amount of roaming population, the second control depends on the population of the estimated roaming carriers, the fourth control depends on the population of expected recovered individuals, and the fifth control depends on the number of confirmed carriers of the virus. The adjoin functions serve as the multiplier of the corresponding state functions and denotes the relative importance of a state function at time $t$. From (43) and (43) it is found that $p_{12}(t)=p_{13}(t)=B_{2}(t-T)$, showing that their importance to the system are linear.

\section{Control strategies and analysis}

As derived in previous section, the optimality conditions of the control problem are presented into three blocks of equations, namely the state systems block (3)-(15), the adjoin systems block (32)-(44), and the optimal control variables ( 31 ) for $i=1,2, \ldots, 5$. As we have to solve three blocks simultaneously, it can be discovered that the control problem possesses unique characteristics. The first characteristic is the existence of mixed conditions, namely the state systems block has a series of initial time conditions as provided in (17) and (18), while the adjoin systems block requires a series of terminal time conditions as given in (25). The second characteristic lays in the fact that the state variables can be solve independent of the adjoin variables. From (23) we can see that the values of $p_{i}$ are not needed to obtain the state variables. It means that we can solve for state systems (3)-(15) forwardly using initial condition (17) and (18). We then solve the adjoin systems by using terminal condition (25) and stored values of state and control variables backwardly in time according to its differential equations. 
Table 4. Control strategy (cons: constant control, opt: optimal control).

\begin{tabular}{cccccc}
\hline Strategy & $u_{1}$ & $u_{2}$ & $u_{3}$ & $u_{4}$ & $u_{5}$ \\
\hline O & cons & cons & cons & cons & cons \\
A & opt & opt & opt & opt & opt \\
B & opt & opt & opt & opt & cons \\
C & opt & cons & cons & opt & opt \\
D & cons & opt & opt & opt & opt \\
\hline
\end{tabular}

Table 5. Initial values.

\begin{tabular}{crr}
\hline Initial state & Scenario 1 & Scenario 2 \\
\hline$S(0)$ & 1752015.2 & 1177227.4 \\
$S_{Q}(0)$ & 8653600.4 & 8703295.6 \\
$E_{U}(0)$ & 17144.0 & 17030.6 \\
$E_{Q}(0)$ & 14740.9 & 27387.1 \\
$I_{U}(0)$ & 10596.5 & 13596.8 \\
$I_{Q}(0)$ & 24909.3 & 65841.6 \\
$I_{C}(0)$ & 1605.8 & 4613.2 \\
$R_{U}(0)$ & 8313.0 & 51711.4 \\
$R_{Q}(0)$ & 34731.6 & 370166.7 \\
$R_{I}(0)$ & 1774.0 & 19597.0 \\
$R_{C}(0)$ & 97.5 & 2257.1 \\
$D_{U}(0)$ & 7822.5 & 76627.0 \\
$D_{C}(0)$ & 173.76 & 528.0 \\
\hline
\end{tabular}

Taking these features into account, we employ forward-backward sweep method to numerically solve the control problem with mixed conditions. Within this method, we use the Runge-Kutta algorithm as a standard ODE solver (Özer 2021). In particular, the sweep method combination with the fourth order Runge-Kutta algorithm perform a good stability and accuracy (Lenhart \& Workman 2007, McAsey et al. 2012). By using the accepted tolerance of $10^{-5}$ for convergence test, we can solve the control problem in 15-20 minutes using standard machine. One who wishes to solve the optimal control problem in more robust, stable and efficient manner than Runge-Kutta algorithm can consider, for instance, Taylor-SPH method (Mabssout \& Herreros 2013) or Homotopy perturbation method (Bayat et al. 2015).

\subsection{Control strategies}

In the first step of simulation, we consider a series of control strategies based on optimal (opt) and constant (cons) control choices as presented in Table 4 . We mean by optimal the control variables which optimally determined within $[0,1]$ according to (31). While, the constant control refers to existing control applied by the Government of Jakarta, of which their estimated levels are provided in Table 3.

The first strategy, denoted as Strategy A, applies all control efforts. The second strategy, denoted as Strategy B, consists of only the first three controls which are quarantine policy and testing policy. The third strategy, denoted as Strategy C, consists of quarantine policy and medical treatment. The fifth strategy, denoted as Strategy D, consists of testing policy and medical treatment. Strategy O as the initial strategy refers to existing control strategy implemented by the Government of Jakarta. This is applied at the same level as the status quo which is already simulated for the model fit in Figures $3 \mathrm{a}, 3 \mathrm{~b}$, and 3c. The parameters used for this simulation are presented in Table 2. We also set $B_{1}=1, B_{2}=1$, $C_{1}=1000, C_{2}=C_{3}=C_{4}=3000$, and $C_{5}=4000$ as the relative importance of each term in the functional objective (19).

To consider the scenario of the government's preparation period, we conducted two time points in which the control policies would be implemented. They are the beginning of the second period $(t=40)$ and the beginning of the fourth period $(t=153)$ and the optimal controls were calculated up to the 
last time point $(t=315)$. For that reason, the initial values for the state system also differ between the control scenario starting at $t=40$ and $t=153$. The initial values for the numerical simulation are presented in Table 5. The purpose of this division in time frames is to assess the effect of time in deciding the optimal control strategy and its effectiveness. This is particularly important as a brief description of when the time is okay to start controlling the system. However, we still assume that the control period has a fixed terminal time $T$. We then presented the dynamics for all compartments.

\subsection{Cost-effectiveness analysis}

In the second step we calculated the cost-effectiveness analysis of each strategy in each scenario to assess the strategy's value economically. We use two cost-effectiveness metrics, namely the average cost-effectiveness ratio (ACER) and the incremental cost-effectiveness ratio (ICER). ACER is the ratio of the total cost and the total benefit generated by an alternative strategy (Agusto \& Leite 2019), while ICER is defined as the ratio between the total incurred cost between one strategy to another and the total incurred benefit from one strategy to another, where the benefit is usually defined as the averted infections through each strategy (Paulden 2020, Biswas et al. 2017).

For the basic cost-effectiveness analysis in this paper, we define the benefit as the total prevented death by each strategy as compared to the initial strategy. While, the cost is defined as the marginal control application cost between each strategy and that from the initial control strategy. It is important to note that the initial control strategy is the initial points for the whole cost-effectiveness analysis. The cost includes the controls application costs and the economic loss due to the number of quarantined individuals. The cost incurred under strategy $k$, denoted by $C(k)$, is calculated according to the following formula:

$$
C(k)=\int_{0}^{T}\left(\left(1-L_{u}\right) w Q_{k}+\hat{c}_{1} u_{1, k}+\hat{c}_{2} u_{2, k}\left(I_{U}+I_{Q}\right)+\hat{c}_{3} u_{3, k} R_{I}+\hat{c}_{4} u_{4, k}\left(R_{U}+R_{Q}\right)+\hat{c}_{5} \mu u_{5, k} I_{C}\right) d t .
$$

In (45), $Q_{k}$ represents the number of quarantined individual for strategy $k, L_{u}$ is the unemployment rate of Jakarta, and $w$ is the lower average wage per individual per day in Jakarta. According to (Plecher 2020), we have $L_{u}=0.0484$ and according to (Salaryexplorer 2020) we have $w=116,667$ rupiahs. It makes sense in a way that the average income in Indonesia is around 1,225, 000 rupiahs per month (Winarso et al. 2015). And as Jakarta is the capital city of Indonesia, it is plausible for Jakarta to have a higher average income per month. The cost of quarantine campaign is assumed to be $\hat{c}_{1}=500,000$ rupiahs for a full intensity of coverage, $\hat{c}_{2}=1,000,000$ rupiahs, $\hat{c}_{3}=1,000,000$ rupiahs, and $\hat{c}_{4}=$ $1,300,000$ rupiahs, represents the price of PCR-based testing cost per individual in Indonesia. Note that $\hat{c}_{4}$ has a higher value as it is not only the diagnostic test but also the antibody test. We set $\hat{c}_{5}=2,760,000$ rupiahs as the medical treatment per individual per day (Jati et al. 2020). Although these calculations rely on several assumptions, it is still beneficial to conduct as it gives a brief description on the most cost-effective strategy.

The benefit contributed by strategy $k$, denoted by $B(k)$, is given by

$$
B(k)=\int_{0}^{T}\left(D-D_{k}\right) d t,
$$

where $D$ is the total death under constant control, i.e., Strategy $\mathrm{O}$, and $D_{k}$ is that under strategy $k$.

The ACER and ICER are then calculated by using

$$
\begin{aligned}
\operatorname{ACER}(k) & =\frac{C(k)}{B(k)}, \\
\operatorname{ICER}(k) & =\frac{C(k)-C(k-1)}{B(k)-B(k-1)} .
\end{aligned}
$$

The calculation results for cost and benefit are provided in Table 6. This table is presented in ascending order based on cost. We can see that Scenario 1 costs more than Scenario 2 as the former is implemented earlier. Within both scenarios, Strategy B costs the most and Strategy D costs the least. 
Table 6. Cost (in trillion rupiahs), benefit (in thousand), and ACER scores.

\begin{tabular}{ccccrc}
\hline$k$ & Strategy & Scenario & Cost & Benefit & ACER \\
\hline 0 & O & 0 & 293.89 & 752.5 & 0.3906 \\
1 & $\mathrm{D}$ & 2 & 298.73 & 1335.4 & 0.2237 \\
2 & $\mathrm{C}$ & 2 & 309.39 & 1320.5 & 0.2343 \\
3 & $\mathrm{~A}$ & 2 & 312.63 & 1347.0 & 0.2321 \\
4 & $\mathrm{~B}$ & 2 & 312.65 & 1346.6 & 0.2329 \\
5 & $\mathrm{D}$ & 1 & 315.98 & 1584.4 & 0.1994 \\
6 & $\mathrm{C}$ & 1 & 324.79 & 1573.2 & 0.2064 \\
7 & $\mathrm{~A}$ & 1 & 326.67 & 1591.9 & 0.2052 \\
8 & $\mathrm{~B}$ & 1 & 326.72 & 1591.4 & 0.2053 \\
\hline
\end{tabular}

Table 7. ICER scores ( $\times$ : dominated strategies, $\times \times$ : extendedly dominated strategies).

\begin{tabular}{ccccc}
\hline$k$ & Strategy & Scenario & ICER $_{1}$ & ICER $_{2}$ \\
\hline 0 & O & 0 & 0.3906 & $\times \times$ \\
1 & $\mathrm{D}$ & 2 & 0.0083 & 0.2237 \\
2 & $\mathrm{C}$ & 2 & $\times$ & $\times$ \\
3 & $\mathrm{~A}$ & 2 & 1.2062 & $\times \times$ \\
4 & $\mathrm{~B}$ & 2 & $\times$ & $\times$ \\
5 & $\mathrm{D}$ & 1 & 0.0141 & 0.0693 \\
6 & $\mathrm{C}$ & 1 & $\times$ & $\times$ \\
7 & $\mathrm{~A}$ & 1 & 1.4327 & $\times \times$ \\
8 & $\mathrm{~B}$ & 1 & $\times$ & $\times$ \\
\hline
\end{tabular}

Based on cost-benefit ratio, Strategy D of Scenario 1 is the most effective as it has the smallest ACER score. For the incremental cost analysis, it can be readily seen that Strategy B of Scenario 1, hereafter Strategy B-1, is outperformed by Strategy A-1, Strategy C-1 is outperformed by Strategy D-1, Strategy B-2 is outperformed by Strategy A-2, and Strategy C-2 is outperformed by Strategy D-2, as the formers require bigger cost to provide smaller benefit. We tag Strategies B-1, C-1, B-2, and C-2 as dominated. The ICER calculation for the next step is given in Table 7. We see that Strategies O-0 and B-2 are extendedly dominated by Strategy C-2 and Strategy A-1 is extendedly dominated by Strategy D-1 as they have higher values of ICER. There are two remaining strategies, further we calculate ICERs for Strategies D-2 and D-1, respectively as follow:

$$
\begin{aligned}
\operatorname{ICER}_{2}(1) & =\frac{C(1)-0}{B(1)-0}=0.2237, \\
\operatorname{ICER}_{2}(5) & =\frac{C(5)-C(1)}{B(5)-B(1)}=0.0693 .
\end{aligned}
$$

Since Strategy D-1 has smaller value of ICER, then we conclude that Strategy D-1 is the most costeffective strategy followed by Strategy D-2. This, however, confirms the similar conclusion based on ACER.

\section{The best control strategy}

Cost-effectiveness analysis based on ACER and ICER concludes that Strategy D-1 is the most effective. We know that Strategy D-1 applies no optimal quarantine policy, instead the rate of quarantine is set constant following the existing approach. However, this strategy increases the testing policy to identify the active carriers and the recovered individuals and effectively prevent more infection and ensure that more recovered individuals are out of quarantine. If we have a look at the number of tests carried out under Strategy D-1 as depicted in Figure 4a and Figure 4b for zoomed version, we can see that the 


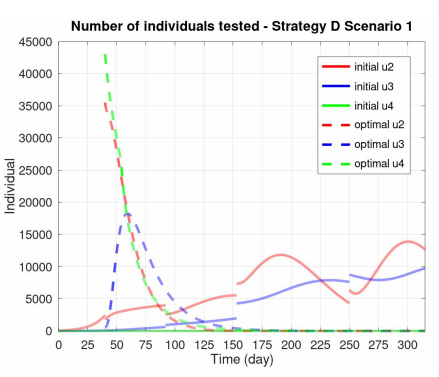

(a) normal version

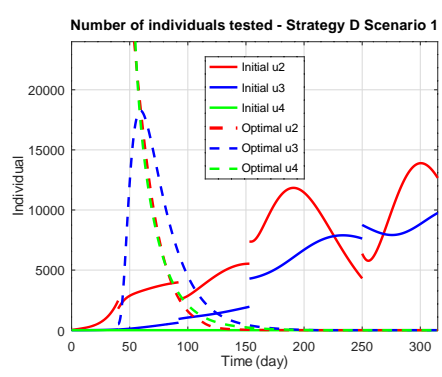

(b) zoomed version

Fig. 4. Number of individuals tested.

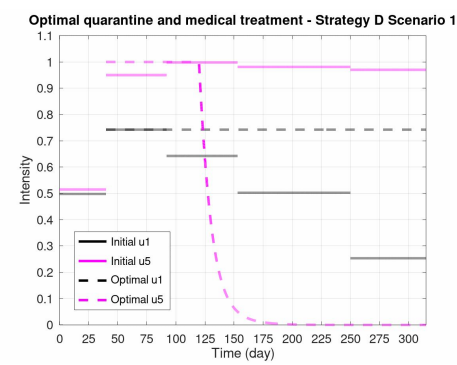

(a) quarantine and medical treatment

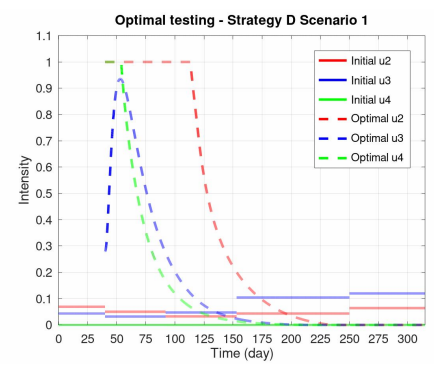

(b) testing

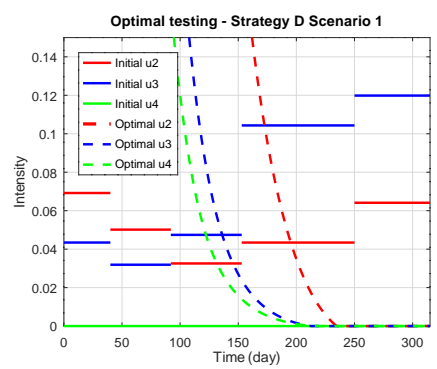

(c) testing (zoomed version)

Fig. 5. Optimal quarantine, testing and medical treatment.

number of tests needs to be increased significantly in a short time frame. This indicates the importance of massive testing compared to a constant rate of testing during a pandemic.

Figures $5 \mathrm{a}$ and $5 \mathrm{~b}$ (including Figure $5 \mathrm{c}$ for zoomed version) depict the intensity comparison between the initial strategy, i.e., constant control, and Strategy D-1. Between day 40 and day 150, the implementation of all controls excluding quarantine/lockdown should be at high intensity. The number of individuals tested for identifying active carriers is around 35,000 individuals a day, reaching maximum on day 40 and then significantly decreased. To identify past infection, the number of individuals tested should be around 42,500 individuals a day on day 40 . The testing to identify the recovered individuals among the confirmed positive individuals should start at a relatively low number, and then increases up to around 17, 500 individuals between day 50 and 75 , then it should be decreased gradually. The quarantine/lockdown campaign needs to remain constant as the strategy imposed. The testing policy is increased to maximum intensity and then decreased after some times. This is also the case for medical treatment as fewer number of people become the active carrier of COVID-19. Although the intensity of quarantine/lockdown is higher compared to the initial strategy, it is not optimally applied.

The controls are meant to reduce the frequency of virus transmission and thus preserve the susceptible population. In Figures $6 \mathrm{a}$ and $6 \mathrm{~b}$, it is shown that the susceptible populations, in general, are preserved by Strategy D-1. This is particularly apparent in Figure $6 \mathrm{~b}$ where the quarantined susceptible population decreases without optimal control and preserved when applying Strategy D-1. This phenomenon is also supported by the dynamics of the exposed population in Figures $6 \mathrm{c}$ and $6 \mathrm{~d}$ where with optimal controls, the exposed populations significantly decrease in a short amount of time. This is because there is significantly lower intensity of virus transmission due to the controls application.

At this point, we could expect that there will be fewer infected individuals as this is true and apparent in Figures 6e and 6f. However, in Figure 7a, the confirmed infected population suddenly increases in a short amount of time due to the massive testing conducted. This, in real life, might be a shocking phenomenon for the public, but it is necessary. In the end, the confirmed infected population also decreases even lower than the initial strategy along with the decrease of the unidentified infected population. The same behavior also exists in the recovered population. It is shown that the recovered confirmed infected population (Figure 7d), roaming and quarantined recovered population (Figures $7 \mathrm{~b}$ and $7 \mathrm{c}$ ) increase con- 


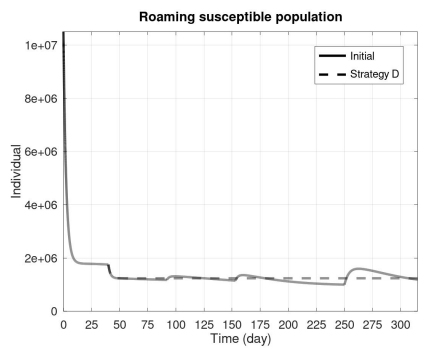

(a) Roaming susceptible

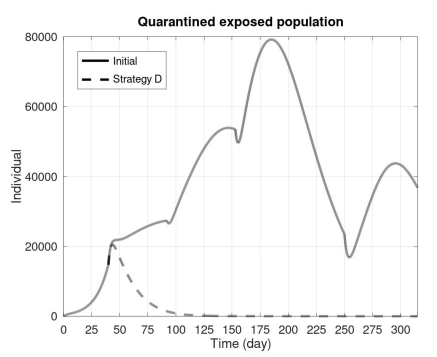

(d) Quarantined exposed

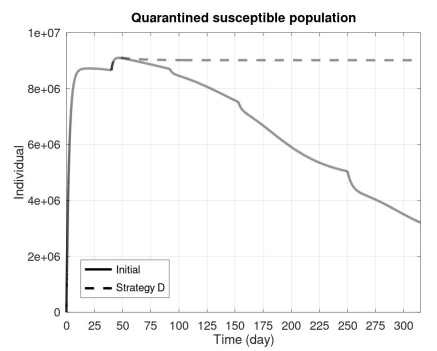

(b) Quarantined susceptible

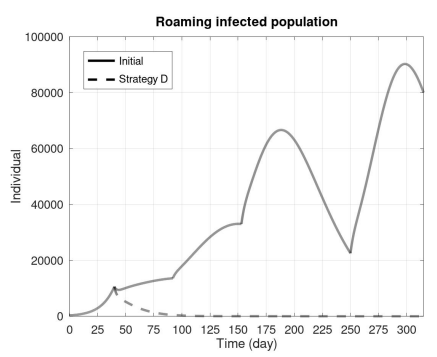

(e) Roaming infected

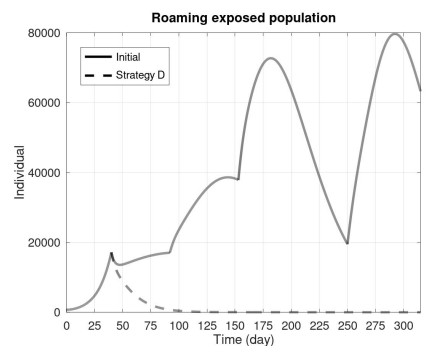

(c) Roaming exposed

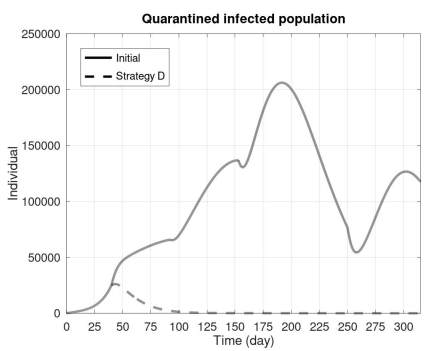

(f) Quarantined infected

Fig. 6. Roaming and quarantined of susceptible, exposed, and infected population.

stantly without intervention while the results of Strategy D-1 are significantly lower than the results of the initial strategy. This is due to lesser individuals got infected and then lesser individuals will have the potential to develop immunity. However, because testing to identify the recovered individuals and past infection, the confirmed recovered population increases in Strategy D-1 (Figure 7e).

Virus transmission prevention is also meant to prevent deaths caused by the virus. Thus, death case becomes important in pandemic management. In Figure $7 \mathrm{f}$ we provided the death case comparison between the initial strategy and Strategy D-1. It is shown that death can be prevented using Strategy D-1 significantly. The confirmed death case is increased significantly by the strategy. This might also be shocking in the short term, just like the result of the confirmed infected population. However, after day 150 onward, the number of death case does not increase and stays at around 1400 compared to 3500 from the initial strategy. In total, the death case can be reduced by as much as 96.9 percent from the initial strategy by using the strategy. This further shows that using massive testing starting on day 40 is effective even without optimal quarantine/lockdown strategy although lockdown still plays its role in preventing virus transmission.

\section{Conclusion}

COVID-19 has been a serious problem worldwide in the year 2020. With many of the characteristics of the virus are still unknown, researchers keep studying the virus while governments try to formulate strategies in managing the pandemic. In this paper, we have developed a mathematical model for COVID-19 transmission with thirteen compartments to accommodate the quarantine and the testing policies. We then fit the model to the infected individuals, recovered individuals, and removed (death) data of COVID-19 outbreak in Jakarta, Indonesia. To control the system, we have introduced five control measures, namely quarantine, testing to identify active carriers, testing to identify recovered individuals, past infection identification, and medical treatment. We have performed simulation of eight different cases depending on the combination of controls and the time frame in which the controls should be applied.

Using Ponytryagin's maximum principle and cost-effectiveness analysis, we have found that the most cost-effective strategy is one does not apply quarantine policy at maximum level, instead applied constantly below the maximum level, which is Strategy D that should be applied as early as possible, i.e., on day 40 after the first identified infection (Scenario 1). This result can be used to infer several concluding remarks. The first remark is that increasing the intensity of quarantine/lockdown causes economic drawback and makes the associated strategy becomes more expensive due to the potential 


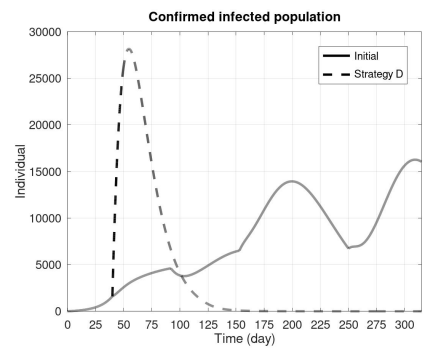

(a) Confirmed infected

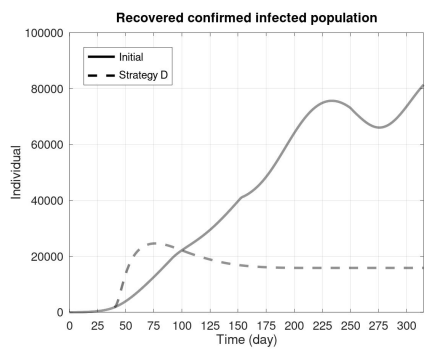

(d) Recovered confirmed infected

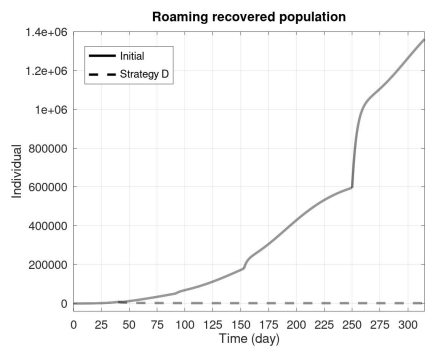

(b) Roaming recovered

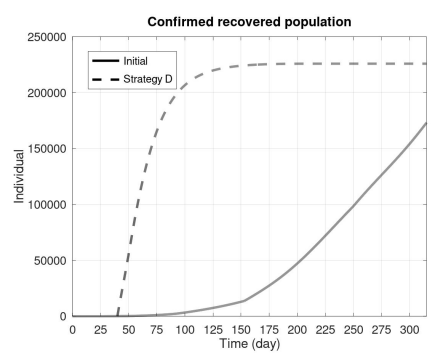

(e) Confirmed recovered

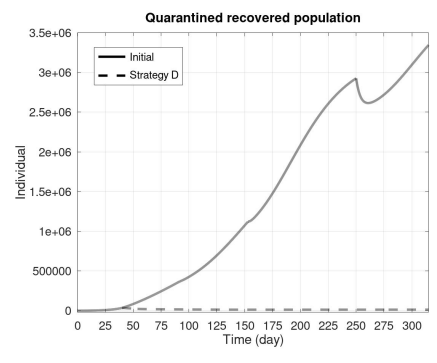

(c) Quarantined recovered

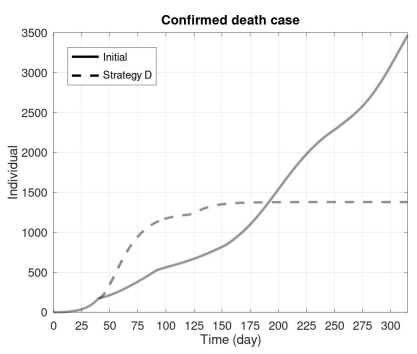

(f) Confirmed death

Fig. 7. Confirmed and quarantined of infected, recovered, and removed population.

economic loss, and thus, it is not necessary to increase quarantine or lockdown intensity. The second remark is that the control methods need to be applied extensively as early as possible as earlier control application will result in higher effectiveness with cheaper cost. This is because we would have a lesser exposed and infected population compared to a later time, and thus, lesser capital needs to be spent for control methods. The third remark is that it is important to consider past infection identification to reduce unnecessary quarantine to some population and prevent further economic loss.

Strategy D in Scenario 1 is shown effective in preventing virus transmission and in the end preventing death. The confirming death case from Strategy D-1 is significantly lower as much as 60.21 percent of the number of death case from the initial control strategy. The total cost, including the potential economic loss, is around 315.98 trillion rupiahs. This is the cheapest alternative compared to other strategies in Scenario 1 defined in this paper. Compared to the initial strategy which costs around 293.89 trillion rupiahs, the total cost including the potential economic loss only increases by around 7.52 percent while we can get more than twice the initial benefit. This is a clear sign that it is significantly more beneficial than the initial strategy. However, in applying the optimal control strategies, there might be several challenges, such as the testing and medical treatment capability. This means that proper preparation is needed prior to the implementation of the control. In this case, to apply Strategy D in Scenario 1, preparation could be conducted at least during the first 40 days since the first day of March 2020. Better preparation can also be conducted earlier than March 2020 with hindsight from other countries.

\section{References}

Agusto, F. B. \& Leite, M. C. A. (2019). Optimal control and cost-effectiveness analysis of the 2017 meningitis outbreak in Nigeria, Infectious Disease Modelling, 4, 161-187, doi:10.1016/j.idm.2019.05.003.

Aldila, D., Khoshnaw, S. H. A., Safitri, E., Anwar, Y. R., Bakry, A. R. Q., Samiadji, B. M., Anugerah, D. A., Alfarizi, M. F., Ayulani, I. D., \& Salim, S. N. (2020). A mathematical study on the spread of COVID-19 considering social distancing and rapid assessment: The case of Jakarta, Indonesia, Chaos, Solitons and Fractals, 139, 110042, doi:10.1016/j.chaos.2020.110042.

Aldila, D., Ndii, M. Z., \& Samiadji, B. M. (2020). Optimal control on COVID-19 eradication program in Indonesia under the effect of community awareness, Mathematical Biosciences and Engineering, 
16(6), 6355-6389, doi:10.3934/mbe.2020335.

Alipour, M. (2017). Numerical study on multi-order multi-dimensional fractional optimal control problem in general form, Kuwait Journal of Science, 44(3), 9-19.

Anastassopoulou, C., Russo, L., Tsakris, A., \& Siettos, C. (2020). Data-based analysis, modelling and forecasting of the COVID-19 outbreak, PLoS One, 15(3), e0230405, doi:10.1371/journal.pone.0230405.

Annas, S., Pratama, M. I., Rifandi, M., Sanusi, W., \& Side, S. (2020). Stability analysis and numerical simulation of SEIR model for pandemic COVID-19 spread in Indonesia, Chaos, Solitons and Fractals, 139, 110072, doi:10.1016/j.chaos.2020.110072.

Araz, S. I. (2021). Analysis of a COVID-19 model: optimal control, stability and simulations, Alexandria Engineering Journal, 60(1), 647-658, doi:10.1016/j.aej.2020.09.058.

Atalan, A. (2020). Is the lockdown important to prevent the COVID-19 pandemic? Effects on psychology, environment and economy perspective, Annals of Medicine and Surgery, 56, 38-42, doi:10.1016/j.amsu.2020.06.010.

Bayat, M., Pakar, I., \& Bayat, M. (2015). Nonlinear vibration of mechanical systems by means of Homotopy perturbation method, Kuwait Journal of Science, 42(3), 64-85.

Bentout, S., Chekroun, A., \& Kuniya, T. (2020). Parameter estimation and prediction for coronavirus disease outbreak 2019 (COVID-19) in Algeria, AIMS Public Health, 7(2), 306-318, doi:10.3934/publichealth.2020026.

Biswas, S., Subramanian, A., Elmojtaba, I. M., Chattopadhyay, J., \& Sarkar, R. R. (2017). Optimal combinations of control strategies and cost-effectiveness analysis for visceral leishmaniasis disease transmission, PLoS ONE, 12(2), e0172465, doi:10.1371/journal.pone.0172465.

Bonaccorsi, G., Pierri, F., Cinelli, M., Flori, A., Galeazzi, A., Procelli, F., Schmidt, A. L., Valensise, C. M., Scala, A., Quattrociocchi, W., \& Pammolli, F. (2020). Economic and social consequences of human mobility restrictions under COVID-19, PNAS, 117(27), 15530-15535, doi:10.1073/pnas.2007658117.

Cao, W., Fang, Z., Hou, G., Han, M., Xu, X., Dong, J., \& Zheng, J. (2020). The psychological impact of the COVID-19 epidemic on college students in China, Psychiatry Research, 287, 112934, doi:10.1016/j.psychres.2020.112934.

Charpentier, A., Elie, R., Lauriere, M., \& Tran, V. C. (2020). COVID-19 pandemic control: balancing detection policy and lockdown intervention under ICU sustainability, Mathematical Modelling on Natural Phenomena, 1557, doi:10.1051/mmnp/2020045.

Cucinotta, D. \& Vanelli, M. (2020). WHO declares COVID-19 a pandemic, Acta Medica, 91(1), 157160, doi:10.23750/abm.v91i1.9397.

Deeks, J. J., Dinnes, J., Takwoingi, Y., Davenport, C., Spijker, R., Taylor-Phillips, S., Adriano, A., Beese, S., Dretzke, J., di Ruffano, L. F., Harris, I. M., Price, M. J., Duttrich, S., Emperador, D., Hooft, L., Leeflang, M. M. G., \& den Bruel, A. V. (2020). Antibody tests for identification of current and past infection with SARS-CoV-2, Cochrane Database of Systematic Reviews, 6(6), CD013652, doi:10.1002/14651858.CD013652.

Demongeot, J., Griette, Q., \& Magal, P. (2020). SI epidemic model applied to COVID-19 data in mainland China, Royal Society Open Science, 7, 201878, doi:10.1098/rsos.201878.

Dinas Kesehatan DKI Jakarta. (2020). Data kasus positif COVID-19 Provinsi DKI Jakarta tahun 2020, Jakarta Open Data, https://data.jakarta.go.id/dataset/data-kasus-positif-covid-19-dki-jakarta. 
Elleby, C., Dominiguez, I. P., Adenauer, M., \& Genovese, G. (2020). Impacts of the COVID-19 pandemic on the global agricultural markets, Environmental and Resource Economics, 76, 1067-1079, doi:10.1007/s10640-020-00473-6.

Fleming, W. H. \& Rishel, R. W. (1975). Deterministic and Stochastic Optimal Control, New York, NY: Springer Verlag.

Ghahremani-Gol, H., Didehvar, F., \& Razavi, A. (2016). Vehicle routing problem for minimizing consumption of energy in three dimensional space, Kuwait Journal of Science, 43(2), 139-150.

Gorbalenya, A. E., Baker, S. C., Baric, R. S., de Groot, R. J., Drosten, C., Gulyaeva, A. A., Haagmas, B. L., Lauber, C., Leontovich, A. M., Neuman, B. W., Penzar, D., Perlman, S., Poon, L. L. M., Samborskiy, D. V., Sidorov, I. A., Sola, I., \& Ziebuhr, J. (2020). The species severe acute respiratory syndrome-related coronavirus: Classifying 2019-nCOV and naming it SARS-CoV-2, Nature Microbiology, 5(4), 536-544, doi:10.1038/s41564-020-0695-z.

Guan, W. J., Ni, Z. Y., Hu, Y., Liang, W. Ou, C., He, J., Liu, L., Shan, H., Lei, C., Hui, D. S., Du, B., Li, L., Zeng, G., Yuen, K. Y., Chen, R., Tang, C., Wang, T., Chen, P., Xiang, J., Li, S., Wang, J., Liang, Z., Peng, Y., Wei, L., Liu, Y., Hu, Y.-H. Peng, P., Wang, J.-M. Liu, J., Chen, Z., Li, G., Zheng, Z., Qiu, S., Luo, J., Ye, C., Zhu, S., \& Zhong, N. (2020). Clinical characteristics of coronavirus disease 2019 in China, The New England Journal of Medicine, 30(382), 1708-1720, doi:10.1056/NEJMoa2002032.

He, S., Peng, Y., \& Sun, K. (2020). SEIR modeling of the COVID-19 and its dynamics, Nonlinear Dynamics, 101, 1667-1680, doi:10.1007/s11071-020-05743-y.

Hezam, I. M., Foul, A., \& Alrasheedi, A. (2021). A dynamic optimal control model for COVID-19 and cholera co-infection in Yemen. Advances in Difference Equations, 108, doi:10.1186/s13662-02103271-6.

Hoffman, T., Nissen, K., Krambrich, J., Ronnberg, B., Akaberi, D., Esmaeilzadeh, M., Salaneck, E., \& Lindahl, J. (2020). Evaluation of a COVID-19 IgM and IgG rapid test: and efficient tool for assessment of past exposure to SARS-CoV-2, Infection Ecology and Epidemiology, 10(1), 1754538, doi:10.1080/20008686.2020.1754538.

Jati, S. P., Budiyono, Budiyanti, R. T., Suhartono, Ginandjar, P., Sritami, A., \& Nandini, N. (2020). Cost estimates related to COVID-19 treatment in Indonesia: what should be concerned?, International Conference on Energy, Environment, Epidemiology, and Information System 2020, E3S Web of Conference Series, 202, 12012, doi:10.1051/e3sconf/202020212012.

Jayani, D. H. (2019). Proyeksi jumlah penduduk DKI Jakarta 2020, Databoks, https://databoks. katadata.co.id/datapublish/2019/12/07/jumlah-penduduk-dki-jakarta-2020.

Jayaweera, M., Perera, H., Gunawardana, B., \& Manatunge, J. (2020). Transmission of COVID-19 virus by droplets and aerosols: a critical review on the unresolved dichotomy, Environmental Research, 188, 109819, doi:10.1016/j.envres.2020.109819.

Jean, S., Lee, P., \& Hsueh, P. (2020). Treatment options for COVID-19: the reality and challenges, Journal of Microbiology, Immunology, and Infection, 53, 436-443, doi:10.1016/j.jmii.2020.03.034.

Kimathi, M., Mwalili, S., Ojiambo, V., \& Gathungu, D. K. (2021). Age-structured model for COVID19: effectiveness of social distancing and contact reduction in Kenya, Infectious Disease Modelling, 6 , 15-23, doi:10.1016/j.idm.2020.10.012.

Kissler, S., Tedijanto, C., Lipsitch, M., \& Grad, Y. H. (2020). Social distancing strategies for curbing the COVID-19 epidemic, MedRxiv, 2020.03.22.20041079, doi:10.1101/2020.03.22.20041079. 
Lenhart, S. \& Workman, J. T. (2007). Optimal Control Applied to Biological Models, Boca Raton, FL: CRC Press.

Li, J., You, Z., Wang, Q., Zhou, Z., Qiu, Y., Luo, R., \& Ge, X. (2020). The epidemic of 2019novel-coronavirus (2019-nCoV) pneumonia and insights for emerging infectious diseases in the future, Microbes and Infection, 22(2), 80-85, doi:10.1016/j.micinf.2020.02.002.

Mabssout, M. \& Herreros, M. I. (2013). Runge-Kutta vs Taylor-SPH: two time integration schemes for SPH with application to soil dynamics, Applied Mathematical Modelling, 37(5), 3541-3563, doi:10.1016/j.apm.2012.08.014.

Madubueze, C. E., Dachollom, S., \& Onwubuya, I. O. (2020). Controlling the spread of COVID-19: optimal control analysis, Computational and Mathematical Methods in Medicine, 2020, 6862516, 14 pages, doi:10.1155/2020/6862516.

Martcheva, M. (2010). An Introduction to Mathematical Epidemiology, New York, NY: Springer.

Mardani, R., Vesmehjani, A. A., Zali, F., Gholami, A., Nasab, S. D. M., Kaghazian, H., Kaviani, M., \& Ahmadi, N. (2020). Laboratory parameters in detection of COVID-19 patients with positive RT-PCR: a diagnostic accuracy study, Archives of Academic Emergency Medicine, 8(1), e43, PMID:32259132.

Martin, A., Markhvida, M., Hallegatte, S., \& Walsh, B. (2020). Socio-economic impacts of COVID19 on household consumption and poverty, Economics of Disasters and Climate Change, 4, 453-479, doi:10.1007/s41885-020-00070-3.

Mazur, M., Dang, M., \& Vega, M. (2020). COVID-19 and the March 2020 stock market crash, evidence form S\&P1500, Finance Research Letters, 38, 101690, doi:10.1016/j.frl.2020.101690.

McAsey, M., Mou, L., \& Han, W. (2012). Convergence of the forward-backward sweep method in optimal control, Computational Optimization and Applications, 53(1), 207-226, doi:10.1007/s10589011-9454-7.

Mehra, A. H. A., Shafieirad, M., Abbasi, Z., \& Zamani, I. (2020). Parameter estimation and prediction of COVID-19 epidemic turning point and ending time of a case study on SIR/SQAIR epidemic models, Computational and Mathematical Methods in Medicine, 2020, 1465923, 13 pages, doi:10.1155/2020/1465923.

Mina, M. J., Parker, R. P., \& Larremore, D. B. (2020). Rethinking COVID-19 test sensitivity - a strategy for containment, The New England Journal of Medicine, 383, e120, doi:10.1056/NEJMp2025631.

Nasruddin R. \& Haq, I. (2020). Pembatasan sosial berskala besar (PSBB) dan masyarakat berpenghasilan rendah, Jurnal Sosial dan Budaya Syar'i, 7(7), 639-648, doi:10.15408/sjsbs.v7i7.15569.

Nurita, D. (2020). Satgas COVID-19: rapid test antigen akan menggantikan rapid test antibodi, Tempo (30 September 2020), https://nasional.tempo.co/read/1391415/satgas-covid-19-rapid-testantigen-akan-menggantikan-rapid-test-antibodi/full\&view=ok.

Obsu L. L. \& Baicha, S. F. (2020). Optimal control strategies for the transmission risk of COVID-19, Journal of Biological Dynamics, 14(1), 590-607, doi:10.1080/17513758.2020.1788182.

Özer, S. (2021). Two efficient numerical methods for solving Rosenau-KdV-RLW equation, Kuwait Journal of Science, 48(1), 14-24, doi:10.48129/kjs.v48i1.8610.

Pacheco, J. (2020). Vehicle routing for the urgent delivery of face shields during the COVID-19 pandemic, Journal of Heuristics, 26, 619-635, doi:10.1007/s10732-020-09456-8.

Paulden, M. (2020). Calculating and interpreting ICERs and net benefit, PharmacoEconomics, 38, 785-807, doi:10.1007/s40273-020-00914-6. 
Pemerintah Provinsi DKI Jakarta. (2020). Daily Update Data Agregate COVID-19 Jakarta, Layanan Darurat COVID-19, http://tiny.cc/Datacovidjakarta.

Plecher, H. (2020). Unemployment rate in Indonesia 2020, Statista, https://www.statista.com/statistics/ 320129/unemployment-rate-in-indonesia/.

Pontryagin, L. S., Boltyanskii, V. G., Gamkrelidze, R. V., \& Mishchenko, E. F. (1986). The Mathematical Theory of Optimal Process, New York, NY: Gordon and Breach.

Putri, R. N. (2020). Indonesia dalam menghadapi pandemi COVID-19, Jurnal Ilmiah Universitas Batanghari Jambi, 20(2), 705-709, doi:10.33087/jiubj.v20i2.1010.

Salaryexplorer. (2020). Average salary in Jakarta 2021, http://www.salaryexplorer.com/salary-survey. php?loc $=1136 \&$ loctype $=3$.

Sebayang, R. (2020). Resmi! Syarat traveling di dalam dan luar negeri saat pandemi, CNBC Indonesia (27 June 2020), https://www.cnbcindonesia.com/news/20200627175013-4-168504/resmi-syarattraveling-di-dalam-luar-negeri-saat-pandemi.

Seierstad, A. \& Sydsæter, K. (1987). Optimal Control Theory with Economic Applications, Amsterdam: Elsevier Science.

Serovaiskii, S. Y. (2004). Counterexamples in Optimal Control Theory, Utrecht: VSP.

Setti, L., Passarini, F., de Gennaro, G., Barbieri, P., Perrone, M. G., Piscitelli, P., \& Miani, A. (2020). Airborne transmission route of COVID-19: why 2 meters/6 feet of inter-personal distance could not be enough, International Journal of Environmental Research and Public Health, 17(8), 2932, doi:doi.org/10.3390/ijerph17082932.

Silva, C. J., Cruz, C., Torres, D. F. M., Munuzuri, A. P., Carballosa, A., Area, I., Nieto, J. J., Fonseca-Pinto, R., Passadouro, R., dos Santos, E. S., Abreu W., \& Mira, J. (2021). Optimal control of the COVID-19 pandemic: controlled sanitary deconfinement in Portugal, Scientific Reports, 11, 3451, doi:10.1038/s41598-021-83075-6.

da Silva, F. C. T. \& Neto, M. L. R. (2020). Psychological effects caused by the COVID-19 pandemic in health professionals: A systematic review with meta-analysis, Progress in Neuropsychopharmacology and Biological Psychiatry, 104, 110062, doi:10.1016/j.pnpbp.2020.110062.

Sohrabi, C., Alsafi, Z., O’Neill, N., Khan, M., Kerwan, A., Al-Jabir, A., Iosifidis, C., \& Agha, R. (2020). World Health Organization declares global emergency: A review of the 2019 novel coronavirus (COVID-19), International Journal of Surgery, 76, 71-76, doi: 10.1016/j.ijsu.2020.02.034.

Sutton, K. L. (2010). Public vaccination policy using an age-structured model of pneumococcal infection dynamics, Journal of Biological Dynamics, 4(2), 176-195, doi:10.1080/17513750903023715.

Tobias, A. (2020). Evaluation of the lockdowns for the SARS-CoV-2 epidemic in Italy and Spain after one month follow up, Science of the Total Environment, 725, 138539, doi:10.1016/j.scitotenv.2020.138539.

World Health Organization. (2020). Transmission of SARS-CoV-2 implications for infection prevention precautions, Scientific Brief, https://www.who.int/news-room/commentaries/detail/transmissionof-sars-cov-2-implications-for-infection-prevention-precautions.

Wilson, N., Corbett, S., \& Tovey, E. (2020). Airborne transmission of COVID-19, The BMJ, 370, m3206, doi:10.1136/bmj.m3206.

Winarso, H., Hudalah, D., \& Firman, T. (2015). Peri-urban transformation in the Jakarta metropolitan area, Habitat International, 49, 221-229, doi:10.1016/j.habitatint.2015.05.024. 
Wu, Y. C., Chen, C.S. \& Chan, Y. J. (2020). The outbreak of COVID-19: an overview, Journal of the Chinese Medical Association, 83(3), 217-220, doi:10.1097/JCMA.0000000000000270.

Zamir, A., Abdeljawad, T., Nadeem, F. Wahid, A., \& Youseff, A. (2021). An optimal control analysis of a COVID-19 model, Alexandria Engineering Journal, 60(3), 2875-2884, doi:10.1016/j.aej.2021.01.022.

Zamir, M., Shah, Z., Nadeem, F., Memood, A., \& Alrabaiah, H. (2020). Non-pharmaceutical interventions for optimal control of COVID-19, Computer Methods and Programs in Biomedicine, 196, 105642, doi:10.1016/j.cmpb.2020.105642.

Zhang, M., Yan, H., Wu, J., \& Zheng, Y. (2020). Quarantine vehicle scheduling for transferring highrisk individuals in epidemic areas, International Journal of Environmental Research and Public Health, 17, 2275, doi:10.3390/ijerph17072275.

Submitted : 03/03/2021

Revised : 25/04/2021

Accepted : 18/05/2021

DOI $\quad: 10.48129 / \mathrm{kjs}$. splcov. 12819 